\title{
BINSWANGER Y EL ANÁLISIS EXISTENCIAL
}

Mario Acosta Gómez*

\section{RESUMEN}

$\boldsymbol{E} l$ presente trabajo aporta novedades de la obra antropológica del psiquiatra suizo Luis Binswanger, en tanto que fenomenólogo mostrando el camino recorrido por este especialista de las ciencias de la intimidad en la búsqueda de un método y una fundamentación filosófica para la psiquiatría, que permitiera reconducir a la unificación de los aspectos intelectual, volitivo y corpóreo del ser humano. Se describe el carácter perfectivo de la esencia del hombre, obtenido mediante la psicoterapia centrada en el análisis existencial propuesto por Binswanger, el cual sugiere la radicalidad de la persona en su inteligir y amar, pero ante todo por situarse frente a la libertad. En el curso del artículo se destacan aportes filosóficos de Leonardo Polo, contrastables con la Psiquiatría instaurada por Binswanger.

\section{Palabras Clave}

Antropología

Hermenéutica

Análisis existencial

Fenomenología

Mundo

Tiempo

Unidad

Realidad

Verdad

Conocimiento

Ser

\section{Introducción}

Al realizar este trabajo tuve en mente, como investigador, el objetivo de mostrar a los estudiantes de postgrado en salud, cómo son compatibles la ciencia -en su sentido de medida de lo sensible- con la filosofía, -en su sentido de inteligir lo existente-. Filosofía y ciencia no riñen. Se trata de conciliar lo temporal con lo intemporal. La vida está en movimiento y corresponde a un trozo de tiempo. Pero si existe lo intemporal, lo estable, lo verdadero, algo en mí es intemporal. Este trabajo registra y analiza hallazgos de la obra del psiquiatra suizo Ludwig Binswanger (1881-1966). L. B. es ante todo fenomenólogo, por tanto en su quehacer científico privilegia lo formal. Sin embargo, todo científico de ciencias naturales o sociales - y la psiquiatría se ubica dentro de estas ciencias - necesariamente hace estudio

* Psiquiatra, profesor investigador de socio-antroplogía Universidad EAN.

Este artículo fue entregado el 8 de septiembre de 2009 y su publicación aprobada por el Comité Editorial el 10 de noviembre de 2009. 
del movimiento sucesivo (la enfermedad es un continuo, tiene partes sucesivas en el tiempo) por lo tanto, consciente o inconscientemente, quiere contemplar integralmente lo conocido, para lo cual ha de considerar lo material como un antes temporal de lo que llamamos fin. Es decir, predice desde los signos y síntomas, que está observando, aquello que según la historia natural de la enfermedad acontecerá después.

La fenomenología es un tema tradicional de la Filosofía, en consecuencia pienso que los aportes hechos a ella por Husserl (fenomenología eidética) y por Heidegger (fenomenología hermenéutica) facilitaron a Binswanger una interesante y ajustada aplicación a la ciencia psiquiátrica. Husserl y Heidegger fueron autores asiduamente consultados por este psiquiatra y considero que en la siguiente afirmación entresacada de una de sus conferencias ya se aprecia, de entrada, el ejercicio del método fenomenológico: "Cuán poco señora de su propia casa es la psiquiatría, y en qué gran medida trabaja esta con capitales prestados... Contempla la salida del caos, mediante un perfeccionamiento en los principios de su investigación y precisamente con una profundización fenomenológica metódica y sistemática... En lugar de afirmar que con nuestras vivencias individuales nosotros pensamos a posteriori la unidad de nuestro yo -y esto acudiendo a la analogía de la unidad de las sustancias externas, por contrapunto-, hoy se reconoce lo contrario, a saber, que nosotros llegamos al concepto de sustancias externas unitarias (como

\section{Abstract}

This paper aims at giving details on the anthropological work of the Swiss psychiatrist Luis Binswanger, focusing on phenomenology, and also showing the road explored by this specialist in the fields of intimacy to look for a method and the philosophical

foundations of Psychiatry. This allows the real need to unify intellectual, volatile and corporal issues of the human being. It also describes the perfection character of the human essence, obtained from the use of the psychotherapy focused on the Existential Analysis proposed by Binswanger. This study shows the radical nature of the human being when loving, but most of all, when he faces liberty. In this paper, we find philosophical contributions from Leonardo Polo contrasted with those made by Binswanger.

\section{KEY WORDS}

Anthropology

Hermeneutics

Existential Analysis

Phenomenology

World

Time

Unit, Reality

Truth

Knowledge

Human being 
portadores de nuestras impresiones siempre cambiantes) solamente porque vivimos tal unidad originariamente en la forma de nuestra unidad del yo propia e independiente, para después, transmitirla secundariamente al mundo exterior. Según esto, nuestra unidad del yo vivida de forma inmediata sería, pues, el prototipo y la protoimagen del concepto de sustancia " ( Binswanger).

Con este aserto, en el fondo, Binswanger depura lo ideal de lo empírico. Esto recuerda a Kant, pero en todo caso es lo que vino a decir Husserl con la exposición de su fenomenología eidética. Binswanger la acoge para dar fundamento a la ciencia psiquiátrica. En el texto citado, con las palabras no muy técnicas prototipo y protoimagen" L.B. está sugiriendo un a priori.

Para aclararlo pensemos en algo que dice Leibniz: "Nada hay en el intelecto que no haya pasado por el sentido, a no ser el propio intelecto". Con lo destacado en negrilla, Leibniz se está refiriendo al inteligir, que desde luego es un a priori (también para el realismo), puesto que coincide con el acto de ser de la persona, cuando con Polo se la considera como inteligir y amor donal. Leibniz no está hablando de la inteligencia pasiva sino de un principio activo. A ese mismo principio se refiere Binswanger cuando afirma: "A la persona interior no conduce ningún camino experimental. Cuando, por ejemplo, con Rorschach (autor muy conocido de tests psicológicos), del número de las respuestas motrices deducimos la inteligencia del sujeto experimental ..." (ACE, p. 311), allí, de nuevo, la persona que da unidad al sujeto, es un a priori. Además se está mirando a lo esencial, a lo eidético, prescindiendo de lo fáctico y se ha llegado a un Yo puro, después de aplicar la llamadareducción trascendental"(Husserl) de la conciencia, la cual no puede ser un yo empírico.

Cuando no hay orden en una ciencia y un centelleo de datos o hechos empíricos pone óbice a nuestra capacidad de saber en profundidad, se requiere un marco de referencia en el cual hagan pie nuestros conocimientos. O como dice Kant en la Crítica de la razón pura: "se puede adelantar mucho reduciendo muchedumbre de investigaciones a la fórmula de una sola tarea".

La psiquiatría no tuvo un cuadro esquemático para sus estudios clínicos hasta el Siglo XVII, cuando el abogado y médico italiano Paolo Zacchias hizo una clasificación que relacionaba trastornos evidentes de la conducta con operaciones psicológicas -percepciones, emociones, memorizaciones -con miras a determinar la responsabilidad legal de ciertas personas-. Los psicólogos del Siglo XVIII habían insistido en la división de las manifestaciones psicológicas del hombre en tres áreas: sujeto sensiente (afectividad), sujeto cognoscente (percepción y pensamiento) y sujeto tendiente (voluntad y tendencias sensibles) (ACE,p.233). Los psiquiatras del Siglo XIX, apoyándose en este esquema procedente en último término de la antropología, habían iniciado la 
elaboración de definiciones psicopatológicas, que servían de unidades de medida para su naciente ciencia. Así surgieron las deficientes definiciones de alucinación como percepción sin objeto y la de manía como juicio erróneo a que se aferra el sujeto a pesar de todas las pruebas en contrario y más tarde la de esquizofrenia, como debilitamiento del poder asociativo.

Mientras Galeno (h.129h.201) en su muy incipiente psiquiatría, solo comprendía descripción de anormalidades notorias de la conducta de los pacientes, la psiquiatría de Zacchias ya intenta dos pasos: descripción cuidadosa de la conducta, seguida de una breve investigación de las principales funciones psicológicas. La psiquiatría del Siglo XIX dio otro paso y abarcó tres estadios: el primero, estudiar los elementos, es decir, proponer como tipos básicos funciones psicológicas elementales perturbadas, tales como alucinaciones, ilusiones, manías, ideas compulsivas y abulia. El segundo, agrupar en formas o síndromes, es decir, hacer una configuración en la cual encontramos combinados diversos síntomas y signos para formar un cuadro clínico, como la depresión, la expansión, la confusión mental y la amnesia. El tercero fue el intento de definir enfermedades mentales concretas. Ejemplo: la parálisis progresiva.

La psiquiatría en el Siglo XIX se ocupó principalmente de esa tarea gigantesca de definir innumerables elementos o síntomas mentales, las varias formas o síndromes y la posible etiología de enfermedades mentales específicas. Al lograr clasificaciones hizo el primer sistema nosológico. Entre los grandes pioneros de esta época de la psiquiatría figuran hombres de la talla de Esquirol, Morel, Kahlbaum, Wernicke y Bleuler, éste último profesor de Binswanger ( Cfr., R. May, E. Angel y H.F. Ellenberger).

Todo progreso científico conduce a nuevos hallazgos, los cuales a su vez plantean nuevos problemas, y así el Siglo $X X$ se vio enriquecido con la psiquiatría endocrinológica, los tests psicológicos, el psicoanálisis y la fenomenología; aportes que querían poner de relieve otros tantos aspectos del hombre. De una parte, Charcot había mostrado que no hay correlación entre la fisiopatología conocida del cerebro y los síntomas neuróticos, que para él sólo tenían origen en reminiscencias de un trauma psíquico, hallazgo éste que condujo a Freud a la exploración psicoanalítica de los recuerdos reprimidos y a la elaboración de su teoría del inconsciente. Por otra parte, y en virtud de los progresos de la química biológica, L.B. podía escribir en 1924: "Vamos tras fórmulas endocrinas unitarias para las concordancias, cada vez más claramente destacadas, entre constitución física y carácter, y en su cambio vemos la etiología de psicosis muy difundidas. La personalidad general puede ser reducida a una fórmula de secreción interna, pero también las realidades anímicas aisladas pueden ser puestas en relación con determinado 
sistema endocrino: así, por ejemplo, la tensión del afecto, con el recto funcionar del sistema adrenalínico; la conducta antisocial de los eunucoides, así como su biotipo, con el trastorno de la maduración de las glándulas sexuales, etc." Binswanger, L.,ACE, p.288). Pero esto sigue siendo ciencia natural, no fenomenología.

En un tercer frente y con el uso de nuevos métodos como introspección dirigida, experimento controlado y medida de lo fisiológico y lo psicológico - lo cual había sido preconizado por Helmholtz, Weber y Fechner - la investigación había culminado en la psicología experimental de Wundt (1832-1920) restringida a la sensación y a la percepción, pero fructífera en el descubrimiento de leyes de fenómenos conscientes provocados por experimentos fisiológicos y con aportes de la psicología comparada entre la conducta del hombre y la de los animales. Por encima de todo, era notoria en Wundt la medida de respuestas a estímulos aplicados en condiciones específicas. En ellas se fijó Galton (1822-1911) quien observó que las diferencias individuales en estos experimentos controlados de laboratorio no eran debidas a error del observador o del instrumento sino que los test de imaginación y discriminación sensorial llevaban a la detección y estudio sistemático de las diferencias entre las personas observadas, con lo que se dio comienzo a la Psicología Diferencial y a los test psicológicos de Binet, McKeenCattell, Rorschach, Kroh y Sperber.

Sin embargo, Psicología Experimental, Psicología Diferencial y Psicoanálisis eran sólo ciencia natural -en clave filosófica diríamos estudio del movimiento físico y sus cuatro principios mutuamente imbricados: lo material, lo formal, lo eficiente y lo final- y esto ciertamente era ostensible como un gran hallazgo de la filosofía y de la ciencia. Pero para Ludwig Binswanger todos los esfuerzos anteriormente enumerados no constituían un suficiente fundamento para el estudio de las enfermedades mentales, y a la vez, para tener un método proporcionado en la investigación de los fenómenos psicopatológicos. Binswanger, piensa bajo la influencia de Husserl, que ese fundamento que él busca es precisamente la fenomenología (Binswanger, L.,ACE, p. 312). Esta no quiere saber nada de lo empírico, si es que queremos llamar así a aquello concreto que está en el mundo extramental o de la realidad bruta: los hechos. Apartarse de los hechos o de los procesos reales es a lo que atiende Husserl con lo que él llama reducción fenomenológica o la puesta entre paréntesis de toda realidad contingente. 


\section{FENOMENOLOGÍA DESCRIPTIVA Y}

FENOMENOLOGÍA EIDÉTICA

En fenomenología conviene decir que todo aquello que aparece o se manifiesta es fenómeno y todo aquel que describe unas apariencias es fenomenólogo (Cfr.Ricoeur, P). Desde 1764, Lambert, discípulo de Christian Wolff, había introducido el término fenomenología como teoría de la ilusión. Kant hace suyo el neologismo al proponerse como tarea circunscribir el dominio del aparecer o fenómeno que para él significa limitada patentización del ser ante un sujeto, según las disposiciones cognoscitivas propias de ese sujeto. Así lo dice Alejandro Llano (Llano, A. p-275). Más tarde, Hegel, en su fenomenología del espíritu publicada en 1807, pretende que fenomenología sea la descripción del camino que el espíritu reconoce a lo largo de la historia, esto es, la búsqueda que el pensamiento realiza de un orden oculto, pero del que llega a establecer su significación absoluta, porque todo lo real es racional y todo lo racional es real. Sin embargo, quien realmente hace de la fenomenología moda es Edmund Husserl, en el umbral mismo del Siglo XX, con la publicación en 1900 y 1907 del primero y segundo volumen de las Investigaciones Lógicas (Raggiunti, R. p.95).

No hay fenómeno sin sujeto cognoscente, pues sólo este puede distinguir entre lo que aparece y lo que no aparece. La observación ingenua de las cosas manifiesta en ellas algunos cambios que todas las personas expresan en el lenguaje corriente. Así el lugar, el color, la figura, el tamaño, etc. sufren modificaciones, mientras quizá en el fondo algo permanece. Cuando se da prioridad a lo que aparece al margen de lo que permanece se habla de fenomenismo. Para el fenomenismo, las diversas formas por las que pasa una cosa, son aspectos de un continuo fluir. La cosa es un conglomerado espaciotemporal de elementos accidentales, que aparecen vinculados transitoriamente y la "idea" no es más que un estado especial de la percepción. El fenomenismo puede ser sólo gnoseológico ó además de gnoseológico, óntico. Para el fenomenismo óntico no hay distinción entre cosa, como elemento constitutivo de la realidad y objeto, que es la cosa en cuanto conocida.

La sustancia espiritual, dicen los seguidores del fenomenismo (no de la fenomenología) es sólo agrupación de fenómenos psíquicos, y el cuerpo lo es de fenómenos físicos. Conceptos, hipótesis y leyes científicas no son fiel reflejo de la realidad, sino representaciones simplistas de los hechos. Tras el fenómeno no existe una cosa en sí velada al sujeto cognoscente. Existe sólo el fenómeno. Tales son las afirmaciones de Ernst Mach (1838-1916), citado por BINSWANGER y partidario del fenomenismo óntico. Sin embargo, para el fenomenismo 
simplemente gnoseológico, más allá del flujo fenoménico subyace una realidad, que llama COSA EN SI. Esta sin embargo es incognoscible en sus determinaciones propias.

En cambio, la fenomenología husserliana (la cultivada por Binswanger) se presenta como intento de conciliación del sentido del ser (léase la cosa en sí) y el sentido del fenómeno léase las determinaciones esenciales de la cosa en sí, que la llevan a ser conocida en su intemporalidad. Husserl es idealista, no realista. El ser de Husserl (que no es el acto de ser de los filósofos realistas) es el ser ideal. La expresión de Husserl de volver a las cosas mismas es equívoca, porque en él significa el ser ideal de las cosas, no su ser real. Para Husserl, el ser real está sujeto a tiempo. Es hic et nunc. $Y$ ese ser real contingente es el que hay que poner entre paréntesis. "En el fondo, la fenomenología nace tan pronto como, poniendo entre paréntesis provisional o definitivamente - la cuestión del ser (del existir empírico), se procede a tratar como un problema autónomo la manera de aparecer las cosas. Se da una fenomenología rigurosa cuando esta disociación es perseguida por sí misma cualquiera que sea su suerte definitiva. Degenera en fenomenología trivial y diluida, por contrapunto, cuando el acto de nacimiento que hace surgir el aparecer a expensas del ser no es enteramente percibido ni tematizado. Bajo el nombre de fenomenología se hace, a veces, tan sólo una presentación popular de opiniones, de convicciones, sin tomar partido por o contra las mismas"
(Ricoeur, P.,o.c.,p.21). Con estas precisas palabras $P$. Ricoeur distingue entre la fenomenología filosófica de Husserl destinada a fundamentar en el ser ideal una psicología y una filosofía según él universales, y la fenomenología corriente, "trivial" o descriptiva, sin pretensiones filosóficas. Veamos cómo ambas son practicadas por Binswanger.

Cáncer es cangrejo en griego, pues ya los pioneros de la medicina académica habían advertido lo descriptivo que era el término para una masa viva, constituida por un cuerpo central y sus prolongaciones irregulares en forma de extremidades, raíces o patas, inicialmente filiformes. La anatomía patológica y la semiología médica acuden continuamente a una analogía de las formas, tomando como análisis principal algo que es fácil de observar en la naturaleza. Se habla del bazo de pórfido (por su semejanza con la piedra preciosa de incrustaciones blancas) o bazo confitado o bazo de sagú. Se describe algún corazón como afelpado, o la vesícula en fresa (puntos de colesterol amarillos sobre un fondo pardusco) o la lengua vellosa (cuando crecen hongos en las papilas gustativas). Un paciente puede tener las tibias en sable; las uñas en vidrio de reloj y los dedos en palillo de tambor. Hay tumores perlados (margaritoma, por sus masas de queratina concéntricas que son como perlas córneas). Los dermatólogos describen la facies leonina o los nevus flammeus (comparación de un lunar con la llama) o el labio leporino por semejanza con el propio de la liebre. 
Un aneurisma o dilatación sacular de una arteria puede tener forma de mora o la misma arteria tener una consistencia de tráquea de pollo. Binswanger, como médico, reconoce que el lenguaje propio de la fenomenología trivial o descriptiva es el metafórico (ACE, p. 219) o analogía de proporcionalidad extrínseca y que esta figura de la expresión verbal o escrita permite una contemplación más simple y más natural de la sintomatología psiquiátrica, cuando mutatis mutandis es aplicada a ella. La manía de los personajes míticos del Olimpo, que precisamente entraban en expansión de su tono afectivo o emocional, dio origen a la noción psiquiátrica de hipomanía (lo rayano en manía, sin llegar a serlo). La paranoia inducida dio origen a la expresión folie à deux, etc.

Binswanger, como todo psiquiatra, hace fenomenología descriptiva, pero lo original en él es la recursividad que manifiesta cuando se trata de conceptos tan necesarios para entender el paciente -como el de mundo-. L.B. accedió a los griegos para estimar la idea que alguno de ellos tenía de mundo. En el fragmento 89 de Heráclito, que como una piedra preciosa es raro y lleno de oscuro fuego, el filósofo de Efeso distingue entre los que están en vela y los que duermen. Binswanger lo interpreta con maestría: los que están en vela (i plural !) tienen un sólo mundo, un mundo común; mientras que entre los que duermen, cada uno (singular) se dirige a su propio mundo ( $A C E$, p. 83). Con este destello L.B. obtiene los conceptos de mundo propio (de introspección o de ensueños), y mundo común o compartido con los semejantes, precisamente aquel mundo que para los esquizofrénicos deja de ser común, porque se refugian en su mundo propio, o mundo, que a otro nivel, puede ser distorsionado por los neuróticos.

"Cuando un enfermo manifiesta haber perdido el mundo o vivir en otro mundo o vivir sólo jirones del mundo o se siente fuera o por encima del mundo, cuando, en exaltación maníaca el mundo se le antoja infinitamente lejano y preñado de futuro o en deprimente desesperación le parece encogido o desmoronado o sin futuro, cuando no tiene ya contacto alguno con el mundo o el mundo se le ha tornado extraño, entonces, sólo entonces, logramos echar apenas una mirada en la complexión de estos modos de vivencia o existencia, en la consideración continua del fenómeno de mundo" (ACE, p.9091). L.B. concluye que el fenómeno de mundo formulado por primera vez en términos científicos debe atribuirse a los griegos y en primer lugar a Heráclito, en la expresión estar orientados al mundo o en otras semejantes.

L.B. dice que Heráclito es el primero en la historia de la humanidad que ha dejado grabada la expresión de la historicidad del existir: Me he buscado a mí mismo (fragmento 101, Diels). Fue el primero en buscar la existencia temporal allí donde está más cerca, en el yo. Sin embargo, vivimos nuestra propia existencia, las mayoría de las veces, en desarmonía con ella, cuando no en disipación. Hemos de reconquistar 
unidad. Vivir, sentir, pensar, tender, requieren unidad. El contacto con la sabiduría como expresión de la verdad y el obrar, según la propia naturaleza, para acceder a una tranquila forma de existir y vivir altamente en unidad de pensamientos y sentimientos solo por pocos es buscado y elegido (ACE, p. 98).

\section{Apoyándose en Husserl,} Binswanger hace también fenomenología eidética o filosófica. No cabe duda que desde Husserl el concepto mundo adquirió enfoques distintos. Ciertamente Husserl dedicó su vida a estudiar el mundo intramental (el de las ideas) como contrapunto del extramental (para él, el empírico). Antes, en relación con el hombre, mundo podría ser sólo ámbito infinito, pues para el existente humano tiene interés toda la realidad, en contraposición a entorno parcial que es lo seleccionado de esta realidad por el animal, como lo necesario exclusivamente para el desarrollo de sus funciones vitales de ser vivo irracional.

Mundo como ámbito infinito no fue el sentido de la idea mundo en la que Husserl quiso centrarse, puesto que el filósofo de Moravia, deteniéndose en lo gnoseológico, buscó más bien fundamentar sólidamente el saber y desarrollar un método distinto al de las ciencias naturales para aplicarlo a aquellas del espíritu. Husserl busca la filosofía rigurosa, dando al concepto mundo el sentido de mundo de la verdad, y verdad autofundada en sí misma. Husserl niega que la verdad se derive del ser real. Para él, el ser es poca cosa.
Es equivalente a hecho. Esta no es la posición clásica o la aristotélica, pues el filósofo griego establece que dentro de los trascendentales, el primero es el ser y el segundo la verdad. De allí su distinción entre ser veritativo y ser real. $Y$ Tomás de Aquino dice que la verdad del conocimiento se funda en el ser y no en el conocimiento objetivo del mismo, tesis central del realismo filosófico: Esse rei, non veritas eius, causat veritatem intellectus (S. Tomás de Aquino).

\section{La Filosofía del Siglo XX} comenzó, pues, mediante una nueva presentación del idealismo: las Investigaciones lógicas de Husserl. Allí este matemático y filósofo pone de relieve que hay leyes lógicas que valen por sí mismas, esto es, desde su propia evidencia. Husserl afirma que dichas leyes no se pueden derivar de procesos psíquicos, aquellos que anidan en las neuronas, sino que son exclusivamente lógicas. Los procesos psíquicos, para Husserl y a mi entender para cualquiera, son procesos contingentes; es decir: no se puede demostrar que la psicología individual humana sea la misma y única en todos los seres humanos. Pero, en cambio, nadie afirmaría que las leyes lógicas puedan ser distintas en éste o aquel ser humano. Por eso, según Husserl, hay que separar lo empírico y lo ideal, o si se quiere, hacer delimitación entre lo contingente y lo necesario. No se trata sólo de invalidar o hacer nulo el psicologismo, esto es, la fundamentación de la lógica en la psicología neurológica humana -psicologismo es cimentar la lógica en procesos reales fisiológicos o 
psíquicos-, sino de depurar lo ideal de lo empírico. Esto es lo que llama Husserl reducción, es decir, quedarse sólo con lo eidético, loideal-queesloexclusivamente intencional- objetivo- (Polo, L.). A esta metodología la llama Husserl volver a las cosas mismas. Pero él no está hablando de cosas reales sino de cosas en la mente. $Y$ en esto consiste el mundo de la pura verdad: "La verdad es el centro de todo el planteamiento de Husserl; y corresponde a la verdad mostrar su propia necesidad. La necesidad lógica es un modo de manifestarse esa característica de la verdad" (Ibidem). Esta necesidad destaca la verdad y lo hace sin que la verdad pertenezca a lo real, en sentido psíquico o cerebral, ni tampoco a los hechos. Husserl no dice que la verdad sea real: la convertibilidad entre la realidad y la verdad no es considerada en su filosofía. Husserl no entiende lo real como verdadero. La verdad se separa de los hechos (Polo, L.). Dicho de otra manera, a la realidad se puede unir la verdad, pero de manera extrínseca.

En conclusión, Husserl ha descubierto un absoluto, un valor necesario, al que se puede considerar sin relación con nada distinto de él. Husserl antes de ser filósofo fue matemático. En las investigaciones lógicas y en su intuición de la fenomenología eidética o filosófica subyace algo que él ha descubierto precisamente como matemático y filósofo. La matemática es ciencia de objetos pensados unificantes. La objetivación del número no corresponde al abstraer ni tampoco a la generalización. Dicho en otra forma: un buen matemático como Husserl sabe que el número no es conocido al abstraer o al generalizar. Cuando estamos ante un montón de manzanas en primera instancia no abstraemos su número. Lo abstraído es sólo un objeto incoativo: es el objeto pensado, en este caso como montón. Pero si se trata de manzanas es posible detectar la manzaneidad. El abstracto de este montón, antes de descubrir la manzaneidad es algo así como lo vasto, que quizá guarda implícita la diferencia que contiene, puesto que es un montón de manzanas. Pero el simple abstracto no es algo exacto en lo que atañe al número de manzanas que hay en el montón. Aquí está en germen la fenomenología que descubre Husserl. Separemos lo empírico, la existencia real de las manzanas y detengámonos en lo ideal, la esencia de las manzanas, la manzaneidad. Y siguiendo con el ejemplo: el conocimiento abstractivo tomado en cuanto tal no incluye propiamente los objetos sensibles. Un matemático, cuando discurre, deja a un lado todo lo sensible. Si considera el tiempo, no tiene que adscribir cualidades sensibles a un continuo espacio-temporal, que para él sólo tiene sentido como una articulación del tiempo, en su estricta índole intelectual. Esto quiere decir que aunque además del inteligir hayan intervenido en sus abstracciones tres sentidos internos (El sensorio común o en su defecto la imaginación, como facultades de presente; la memoria como facultad de pasado y la estimativa o cogitativa como facultad de futuro), el matemático no se detiene en la conjunción sensible pasado-presente-futuro, sino que 
directamente articula el tiempo. Pero esto es lo mismo que detectar eidéticamente el tiempo. Se trata de un tiempo ideal y no de un tiempo real. $Y$ si en lugar de tiempo hablamos de número pensado tendríamos que considerarlo como una propiedad relacional (Posada, J. M). Esta propiedad, como tal, también escapa a lo físico, igual que la articulación intelectual del tiempo. Es decir: los objetos matemáticos son hipótesis de lo físico. Por aquí creo que se ve de nuevo la depuración de la idea con respecto a lo físico, la delimitación de campos entre lo ideal y lo empírico. Y también captamos lo proclive que estaba Husserl, como matemático, para deslindar los dos campos.

\section{NO HAY ENFERMEDAD SiNo ENFERMOS}

Y... ¿Qué tiene que ver lo anterior con el mundo en el cual se mueve un psiquiatra? Pues mucho. Un psiquiatra tiene pacientes. Los pacientes están en la realidad, en el mundo empírico. Son de carne y hueso. Sin embargo el psiquiatra, para tratarlos, tiene que acudir a la idea de enfermedad, que como concepto está en su mente. El psiquiatra sabe que no hay enfermedades sino enfermos, pero cuando descubre la idea esquizofrenia, ha de aplicarla a algún enfermo que está en la realidad: aquello que sensiblemente se mueve; no obstante, la idea esquizofrenia es algo inmóvil, intemporal. Para un psiquiatrafilósofo, como Binswanger, esta doctrina de distinguir lo verdadero como algo perteneciente sólo al mundo intramental, de lo real como algo contingente es apasionante. Sin embargo, para L.B. la persona esquizofrénica es ante todo persona. El es un humanista y cultiva lo concerniente al espíritu. Reconoce la relación de la criatura con el Creador. Distingue los dos sentidos del ser creatural. Ser cósmico y ser personal. Ya lo vimos en el primer texto que citamos de él en este trabajo. Es obvio que para Binswanger, persona y esquizofrenia no son convertibles entre sí. El trabajo del psiquiatra consistirá en apoyarse en lo que él conoce como esquizofrenia, en su mundo intramental, para de algún modo lograr negarlo en aquella persona de carne y hueso, mediante una curación o al menos paliando las manifestaciones empíricas de esta enfermedad. Al volver a las cosas mismas (los seres ideales, según la fenomenología) el psiquiatra redescubre en su conciencia la intención de objeto y si es fenomenólogo eidético considera la conciencia también como algo a priori. Al descubrir la conciencia, la reconoce como conciencia de. $Y$ aquí entra a operar otra reducción de Husserl, pues esa conciencia no puede ser empírica sino eidética. Es la misma 
unidad del propio yo de que habla Binswanger. También esto estaba en el primer texto que citado en este artículo sobre L.B.

Con lo anterior de ningún modo se ha dicho que Binswanger, quien llama a la psiquiatría "ciencia curativa de las almas" (Binswanger, ACE, p. 289), haya eludido una psicología de la persona o una psicología científico-espiritual que estudie al hombre centrándose en las operaciones propias de la vida, llamadas exactamente acciones inmanentes. Hay una superioridad del ser que no se agota en las acciones, ya transitivas, ya inmanentes. Es la superioridad de la libertad. Sería error ajeno a un psiquiatra de su talla estudiar al hombre sólo mediante movimientos transitivos, donde un agente obtiene su efecto fuera de sí mismo (actio in passu se dice en la terminología filosófica). L.B. tiene muy claro que la vida espiritual es la más alta y es propia del hombre, único ser que dotado de cuerpo material y alma espiritual tiene unidad y plenitud subjetiva (ACE, p.316), y así lo decía este psiquiatra suizo-alemán citando a Cassirer y contradiciendo a Freud, en su conferencia sobre la psiquiatría ante los progresos de la psicología moderna, en 1924: "En lugar de demoler la unidad de nuestro yo, lo que nunca acontece -por otra parte- sin autoengaño científico, para después, en el mejor de los casos, $<$ deducirla $>>$ de nuevo a posteriori de las ruinas $0<<$ interpretarla $>>$ a partir de tales ruinas, la nueva psicología tiene el valor de reconocer la vitalidad inmediata de la unidad de nuestro yo" (ACE, p. 306-
307)... "Con otras palabras, en lugar de querer penetrar en el problema de la subjetividad a partir de la objetividad, lo que solo es posible mediante una especie de reconstrucción, resulta ahora más fácil la exigencia de comprender la objetividad a partir de la subjetividad" (ACE, p. 311). Dicho de otra manera: cuando la ciencia natural de su época quiere presentar el alma humana como función del cerebro o como proceso de la naturaleza, L.B. aspira desde la ciencia misma y desde la filosofía a mostrar la existencia del espíritu como algo absolutamente distinto de la materia, esto precisamente ateniéndose a las operaciones inmanentes de la vida anímica del hombre, que permiten determinar una pura función de lo espiritual. El espíritu es lo atemporal, la materia es lo temporal.

Al encontrarse con esta gran verdad, Binswanger no renuncia a la perfecta unidad de cuerpo y alma humana, en razón a que aprecia en esta unidad la plenitud de un ser individual, de una persona. Por los caminos de la ciencia psiquiátrica y precisamente porque su objeto de estudio es el hombre anímicamente enfermo, Binswanger vislumbra el concepto histórico de persona: rationalis naturae individua substantia (Boecio). Y afirma que su psicología será una psicología de la persona. Ahora bien: no se puede hacer psicología de la persona, sin recurrir a la filosofía en busca de las nociones necesarias para entender una realidad tan compleja como el ser personal -y menos encerrándose en la esencia-. Pero Binswanger ha sido deslumbrado 
por la fenomenología eidética, la cual no brinda las bases suficientes para estudiar la persona humana. La fenomenología al permanecer solo en lo eidético abandona el acto de ser del existente humano. La fenomenología tampoco accede a la distinción real essentia-esse y no distingue entre acto de ser cósmico y acto de ser personal.

\section{De LA FENOMENología eidética a LA FENOMENOLOGÍA HERMENÉUTICA}

Mundo, en la experiencia total del hombre no es sólo ver, tender con aprioridad a los objetos mentales que están en presencialidad, porque el hombre también mundea y palabrea y por eso no es sólo apertura para lo que es verdad, sino también para lo que deviene. Algo acontece fuera de la mente del hombre (lo extrapsíquico) cuando este empieza a experimentar o cuando empieza a hablar, por lo tanto es parte del problema de la intersubjetividad, imprescindible para un psiquiatra, pues lo interpersonal es noción necesaria para el hombre en sociedad y sociedad equivale a convivencia. El hombre, además, coexiste con su hábitat.

No podemos detenernos sólo en objetivaciones, en las presencialidades constatadas por nuestra mente, en lo patente, porque también está delante la patencia de la no patencia y ya tenemos resonancias heideggerianas. Husserl y Heidegger condujeron a Ludwig Binswanger, psiquiatra que nació y murió en Kreuzlingen (Suiza), sin ser un gran viajero, pero sí un gran estudioso, a sacar del limbo la psiquiatría de su tiempo, tan necesitada de certezas como ciencia, pues uno de los sentidos de la palabra ciencia es conocimiento cierto a través de determinaciones ciertas. Pero en la ciencia científico-natural la relación causaefecto es sólo contrapunto con respecto al pensar propio de la fenomenología. Rescatar la filosofía de una manera neta, como lo hace Husserl, trayendo a colación la verdad como valor absoluto -como dotada de necesidad y evidencia intrínseca- es huir del empirismo, postura que ya había sido rectificada, en parte, por Brentano, maestro de Husserl. Y Binswanger está de acuerdo con esta rectificación hecha al empirismo. Pero para un pensador como él, que también ha accedido a los filósofos clásicos, la prioridad absoluta de la verdad no es admisible, porque ello niega que verum in esse fundatur (la verdad se funda en el ser). Biswanger se desconcierta, como muchos discípulos de Husserl, cuando este acentúa su idealismo. Y recurre a Heidegger, interpretándolo inicialmente como filósofo de la realidad. Esto es: aunque preguntar primordialmente por el sentido del ser -como hace Heideggersiga teniendo connotaciones idealistas, 
ese acudir del filósofo alemán a un punto de vista práctico, ser-en-el-mundo, expresión también heideggeriana, deja sitio a la pragmática, y esto ya permite a Binswanger hacer simultáneamente psiquiatría y filosofía y plantarse en el mundo real.

La fundamentación meramente lógica de la verdad, trae problemas para el ejercicio de la psiquiatría. No se puede abrir un abismo entre la verdad y el ser real. No se puede interpretar el ser como estrictamente contingente. Cierto es que en la realidad extramental está lo efímero, pero también hay en ella un algo permanente, fundante, que actúa como nuez, como meollo de todo cuanto existe. $\mathrm{Si}$ lo extramental es exclusivamente contingente, la verdad sobre ello es pura ficción y esto es nominalismo: "voces, praeterea nihil " diría elegantemente un filósofo dellenguaje. Como históricamente el idealismo ha sido una reacción contra el nominalismo, se entiende la reposición del idealismo, al comienzo del Siglo XX, para salvar la filosofía, maltrecha por el empirismo del Siglo XIX. Pero ese no es un suficiente modo de salvarla (Polo, L.).

El correlato entre lo ideal y el sujeto enfermo no es primariamente lo psíquico. Antes está la expresión de lo psíquico, que no puede ser tan sólo un nombre. Para Binswanger, el problema de la constitución de la ciencia particular, no puede resolverse afirmando que lo real es meramente empírico y contingente, y a la vez aseverar que lo verdadero es solo lo lógico. Cabe ponerlos en relación y no simplemente desde fuera (extrínsecamente), sino también desde dentro. A esta concreta cuestión se dedicó L.B. a partir de la aparición de Ser y tiempo, en 1927. Binswanger sufre una radical transformación ante el movimiento existencial iniciado por Kierkegaard y con varios de sus colegas psiquiatras -siguiendo las directrices de Heidegger- elabora una nueva manera de entender la psiquiatría y también la realidad: el Análisis Existencial.

Binswanger aprovecha la discrepancia entre Husserl y Heidegger: este ha descubierto como fenómeno algo que Husserl no ha detectado: la patencia de la no patencia por tanto, la necesidad de preguntar. En algo tan obvio está el quicio del análisis existencial. La inclusión de la pregunta al constatar lo no patente, lo que se oculta detrás del fenómeno. Fenomenología hermenéutica quiere decir sentido subordinado a un sentido del ser, por el cual hay que interrogar, puesto que todavía no se sabe. Allí está la confianza en la descripción hecha por el mismo paciente psiquiátrico y a la vez la búsqueda a través de todas sus expresiones lingüísticas, cinéticas, alucinatorias, ilusorias, oníricas... Allí está la afirmación de Binswanger de que el sueño es un mundo propio (patencia) del que es preciso despertar (no patencia) al paciente para traerlo al mundo común: se trata de aclarar el modo de existencia diferente del enfermo, partiendo de sus experiencias, sin prisas, hasta dar con la clave del sentido que se oculta al analista y al paciente mismo, huyendo del prejuicio y de toda teoría preconcebida. 
Otra cosa es que se llegue siempre a conocer esa clave. Pero aquí se ha retornado al ser como principio de la inteligibilidad. Es la tradicional fórmula esse et unum et verum et bonum convertuntur. Es decir: con el Análisis Existencial Binswanger aplica a la psiquiatría un método que tiene sus raíces en el clásico orden trascendental que da la preeminencia al ser. No prescinde del todo de la fenomenología de Husserl, puesto que Binswanger sigue sosteniendo que para estudiar al hombre anímicamente enfermo es necesaria una concepción ONTICA del ser humano, es decir, plantearse filosóficamente una esencia "situada" del hombre.

Pero al estudio de la causa formal o de la esencia ahora Binswanger incorpora la hermenéutica de Heidegger, que como es sabido también tiene su antecedente en Aristóteles. En su sentido primordial hermenéutica no es sólo interpretar, sino anunciar y enunciar el lugar propio de la verdad. Para Aristóteles el anuncio enunciativo es el juicio - algo que tiene que ver con la expresión, con el habla, con la pregunta como método interrogativo y su repuesta. También el juicio tiene que ver con el diagnóstico. Un diagnóstico es un juicio que anuncia y enuncia.

La hermenéutica es así mismo diálogo: encuentro en las profundidades del ser, es la psicoterapia para Binswanger. Y la hermenéutica es diálogo, porque la interrogación por el sentido que está oculto reclama una respuesta. En torno al diálogo, implícitamente está lo auditivo, que es distinto de lo visual, emparentado esto último con la teoría de la objetivación, esto es, lo aparente del fenómeno. La contraposición a lo que aparece es lo que no aparece todavía, pero que quizá aparezca con la interrogación y la escucha del paciente. $Y$ de nuevo se ve aquí la coincidencia con lo que es la filosofía para Heidegger: una filosofía que quiere decir entender al modo de oír, por contraposición a la filosofía de Husserl, que justamente quiere ver solo eidos.

Heidegger - olvidando que la Metafísica tiene un quiebre en la historia, que la divide en clásica y moderna- le achaca globalmente el olvido del SER, al omitir la pregunta que interroga por el ser, que Heidegger dice no ha formulado por estar sumergida en la metáfora visual. $Y$ con esa crítica arrastra a Binswanger, quien ya descorazonado con el neokantismo de sus mentores en psicología, desconfía -aún más después de Heidegger- de todo saber sólo objetivante (ACE, p. 220-221 y 437).

Husserl, para Binswanger, seguía prisionero del fenómeno que aparece ante un poder de manifestación, que es el de la visión. Pero ahora la hermenéutica le viene a recordar que a la metáfora de la visión es preciso unir la metáfora de la audición, y la fenomenología entonces se hace noticia o fenomenología hermenéutica. Interrogar es dar al ser la iniciativa, y así el analista existencial trata con su paciente de tú a tú, porque si hay una respuesta, la respuesta solo la puede dar el ser. Deslizarse de la 
teoría a la audiología da preponderancia al lenguaje, tanto oral como gestual o incluso corpóreo como es el caso de los síntomas y signos histéricos: el ser es actor.

Por otro lado, aunque el tiempo como horizonte de la comprensión del ser (Heidegger) tenga una connotación - objetiva - presencialidad articulante del pasado y futuro, que permite establecer objetos referibles a quididades sensibles, esta misma determinación extática del tiempo hace que la inteligencia note que ella no se agota en articulaciones temporales.

Es decir: cuando Binswanger articula los objetos propios de la memoria (facultad de pasado), la cogitativa (facultad de futuro) y la imaginación (facultad de presente), logra quididades sensibles, tales como cuerpo vivenciado, psicosis, neurosis, etc. Pero la inteligencia capta que estas articulaciones temporales no la saturan. $Y$ también capta que tales quididades sensibles no agotan la realidad. Luego los abstractos ni saturan la capacidad de pensar, ni ahondan en la realidad hasta captar la esencia de lo singular, que permanece inefable, según Binswanger. Pero es que además de esencia hay acto de ser personal.

Binswanger se está encontrando con la natural limitación de la finitud del hombre. Esto, sin embargo, no lo desconcierta, pues no va a caer en el extremo de prescindir de lo óntico, la esencia, algo también necesario para su ciencia psiquiátrica. $Y$ aunque toma los apuntes ontológicos de la analítica existencial de Heidegger, sobrepasa el ser-en-el-mundo-finito del pensador alemán, con el ser-allende-elmundo (ACE, p. 92), hallazgo propio de Binswanger - con el que aspira trascender a Heidegger- y el cual entiende como apertura a Dios en la eternidad, y a los hombres en el tiempo mediante el amor. El amor tiene siempre razón de otro. El espíritu no puede estar sólo. Ser existente no es un asunto pacífico, pues aunque esté abierto a todo -el alma es en cierto modo todas las cosas, según Aristótelesen definitiva a quien tiene que poseer es a sí mismo para autodestinarse a los demás y a Dios. Y eso sólo es logrado en la medida en que abdique de ser yo mismo en soledad. Es decir: el existente humano se posee para poder convertirse en amor donal. En una conferencia cimera Binswanger afirma: el estilo de la personalidad es amor a la unidad de corazón, alma y razón; de yo y tú; de yo y Dios; de yo y mundo, de tiempo y eternidad (Münchenbuchsee,5-VI-1946). Hay aquí añoranzas y realidades: armonía del ser humano consigo mismo y en la intersubjetividad, también con los demás hombres; ciertamente armonía con su entorno físico y con la cultura y la historia, pero sobrepasándolo todo, amistad del hombre con su Creador. 


\section{Conclusión}

No obstante la vocación de fenomenólogo, asentida por él, Binswanger hace manifestaciones que se podrían llamar de filosofía realista, pues en sus últimos escritos contempla el SER como un a priori, sin minimizar por ello su afirmación en torno a que la psiquiatría debe encontrar con su trabajo la unidad formal de la esencia humana. Desde 1934 ya no está seguro de la fenomenología eidética de Husserl, a la cual había acudido desde 1922. Considerando que después de 1927 admira a Heidegger, cuya fenomenología se puede calificar de hermenéutica, busca también en los presocráticos, principalmente en Heráclito, el camino para hallar esa unidad esencial del hombre. Heráclito, a pesar de sus enigmas le proporciona atisbos para entrelazar el cuerpo humano vivo, también el anímicamente enfermo, con el inteligir, el sentir y el tender del hombre. En el pensador griego, sin embargo, sólo encuentra expresiones que indican que no hay división absoluta en el todo, ese que se mueve ante nuestros sentidos, que los pares de opuestos, así sean aparentemente inconexos, también llevan a la unidad, que lo entero es lo mismo que sentido en general y es constitutivo de un todo continuo, y que superficialmente hay en esa, la realidad que se mueve, aspectos discretos 0 plurales. Esta es la unidad de lo físico, la unidad de orden cumplido del cosmos, que no es la que busca Binswanger, porque pretende remedio para esa unidad más alta: la esencial del ser humano.
Sin embargo, Binswanger, pronto descubre que el existente humano es aspiración a la posesión infinita. Y que en la donación absoluta puede encontrarse correspondencia. La persona humana interviene dando, aportando, fomentando, incrementando el orden histórico y el orden del universo, haciendo que lo que no era, sea. Todas estas son sugerencias en torno a un ser-en-el mundo-allende-el-mundo, pro-puesto por Binswanger, que él lo centra en el amor.

Binswanger, ante el ser creatural, tiene claro que el ser humano es más que el universo, pero no avizora la doctrina del intelecto agente, según la cual inteligir es ser. El espíritu, como entidad finita, tiene también remedio en el entender, no sólo en el amor. No es lo mismo ser inteligible en acto que tener la realidad que tienen las cosas: ser entes. En la antropología trascendental aportada por Leonardo Polo, para ser inteligible en acto se precisa ser intelecto agente. La perfección que está en la cosa no está en la mente. $Y$ hay otra perfección que está en mí mismo, en cuanto origen de mi inteligibilidad. Esto debe ser elaborado. El acto del inteligible, que es la luz del intelecto agente, primero es iluminación y después aparece objetivamente, como consecuencia de la operación intelectual. Y la operación que hace posible el conocimiento supone un sujeto cognoscente, unas facultades cognoscitivas orladas por hábitos, unas operaciones de esas facultades y un término de estas últimas, denominado 
objeto pensado, que puede ser signo de la cosa en sí, pero no es igual a ella. Es el ser veritativo equiparado al ser objetivo. Este último, en el realismo, es sobrepasado por el ser real.

Binswanger no encuentra en la filosofía moderna fuentes para descubrir que además del conocimiento objetivo existe el conocimiento habitual, en donde los hábitos son perfección de la potencia operativa en orden a su perfecta operación y mejor aún perfecciones por las cuales la facultad se pone a disposición de una libertad trascendental, que es mi propio ser (Polo,L., Seminario de Doctorado, Pamplona, España, [9 al 15] XI-78).

Al conmemorarse casi nueve lustros de la muerte de Ludwig Binswanger reitero que pretendo honrar su memoria con este somero trabajo que privilegia la psiquiatría humanista, siguiendo el método del Análisis Existencial creado por Binswanger y su escuela. Acometer este estudio, en donde hube de encontrar nexos entre el comprender y el explicar en el estricto sentido que les otorga la filosofía alemana a estas nociones, no hubiera sido posible sin acudir a nociones de una Antropología trascendente, que tuve al alcance gracias al profesor Leonardo Polo Barrena, cuyas lecciones oralesen las que él ha vertido sus profundos descubrimientos acerca del acto de ser personal- me brindaron una especial coherencia para que al seguir después sus obras escritas distinguiera, en primera instancia, este acto de ser de la persona humana, que es libertad, de aquel otro acto de ser cósmico, cuya esencia es movimiento sucesivo en programa tetracausal. $Y$ en segunda instancia, pudiera diferenciar entre pensamiento objetivante y pensamiento habitual. De allí, que el presente artículo, además de sus aportes a la salud mental, se alcance a inscribir en la Teoría del Conocimiento. La lectura que se hicieron de obras de filosofía, citadas por Binswanger, algunas publicadas no muchos años después de aquellos en que el psiquiatra suizo concluyó su producción intelectual, hacia el año 1960, me condujeron a comprobar la necesidad de nuevos métodos para hacer cala en la realidad cognoscible.

La propuesta que Polo ha presentado desde 1964 y aún antes, es que el pensamiento objetivante deviene insuficiente para acceder a la realidad. Es necesario trascenderlo, sin dejar de aprovechar todo lo que nos pueda seguir brindando. Es verdad que actualmente las objetivaciones especifican las ciencias y por pertenecer estas al ámbito de lo mental considero que este trabajo también alcanza a inscribirse entre los que se dedican a la filosofía de la mente. Pero en definitiva he querido decir que la verdad no puede estar reñida con el estudio de la realidad situada más allá o más acá de la mente y sus objetivaciones. Sin el recurso a la realidad, toda verdad, obviamente también la psiquiátrica, perdería su fundamento. Cuando acudimos al pensamiento objetivo y no lo apreciamos en sus justos límites, existe peligro de caer en representacionismo y olvidar que la verdad es un trascendental fundado. Pero un trascendental fundado no se autofunda. La fundamentación meramente lógica de la verdad trae problemas. Es preciso descubrir los métodos que nos conduzcan a fundar el conocimiento en el ser real, directamente. 